\title{
Investigating China and United States Students Cultural Learning Beliefs: Focus on Habits and Time Factor
}

\author{
Edeh Emmanuel Chidiebere* \\ College of Chinese Language Studies, Zhejiang Normal University, China
}

Received: 畊 October 22, 2018; Published: 制 October 29, 2018

*Corresponding author: Edeh Emmanuel Chidiebere, College of Chinese Language Studies, Zhejiang Normal University, China

\begin{abstract}
Chinese students are generally known to be working harder, spending more time on academic activities and having a stronger commitment to educational goals than their American counterparts. The Confucian culture of learning, coupled with social and economic pressures, compel Chinese youths to place much greater emphasis on educational attainment. Drawn on survey data gathered from university students in both the USA and China, this study explores how study habits formed during school years affect time allocation decisions made by university students. We use samples of Shanghai and NYC college students to investigate young adults' perceptions and attitudes toward the allocation of time between independent academic activities (studying and reading) and non-study activities (social networking, video gaming, and TV watching). The results appear to support claims that Chinese university students spend a greater time on independent academic activities than their US counterparts.
\end{abstract}

Keywords: USA China, College Students, Time Use, Academic Activities, Study Time, Reading Time, Digital Media, Video Gaming

\section{Introduction}

The objective of the present study is to shed light on the differences between Chinese and American college students' attitudes toward learning. In addition, this study explores students' perception of the trade-off between the time they spend on digital media and the time they spend on reading and studying. This topic is important because in the race between China and the USA to improve their economic competitiveness, educational outcomes are imperative. Technological sophistication, financial erudition, and political acumen that are expected from today's students are very much a function of their academic performance, which, in turn, depends on the students' attitudes toward learning. It is often assumed that Chinese students spend more time studying, especially in comparison to their American counterparts as the latter are more involved in extracurricular activities and are not as much under pressure from their parents. This paper attempts to answer the question of how these "stereotypical" intercultural differences are reflected in the differences in study habits of college students in China and the USA. The authors compare two samples of college students with similar backgrounds and majors at two urban universities with comparable academic levels, settings, and national rankings. The study provides empirical evidence that helps to understand how American and Chinese college students differ in the way they allocate their time between activities that lead directly to their scholastic achievement (independent studying and reading) and those activities that either crowd out their time away from studying or do not provide direct explicit benefits toward their academic performance, such as computer gaming and surfing social networks.

\section{Previous Empirical Evidence}

Growing up in a culture that has been rooted deeply in a tradition of learning and scholastic competition for thousands of years and pushed hard by their parents, Chinese students work more diligently than their American counterparts [1-4]. They are also more avid and proficient readers. According to one study, in 2009, a Chinese citizen on average reads books for 15 minutes, newspapers for 21 minutes, and magazines for 16 minutes every day. This amounts to almost an hour of reading daily. For young people, readership rates are much higher [5]. American culture does not place the same emphasis on the importance of education or reading. The National Endowments for the Arts (2007) reported that in the US, 15- to 24-year-olds (high school and college students) spend only 7 minutes reading on weekdays and 10 minutes on 
weekend, on average. By contrast, they spend 2 to $21 / 2$ hours per day watching TV [6]. The same report pointed out that $65 \%$ of college freshmen read for pleasure for less than one hour per week or do not read at all [6]. Contrary to the assumption that the students' focus should be studying, leisure activities take up most of their time. [7] polled students at Rutgers University and found that most of them spent 8-12 hours per week studying and twice as much time on leisure activities. He also found that $25 \%$ hardly study at all. Studies cite that the major culprit behind the recent trends in students' reading and studying habits is the development of digital technology and the Internet [8]. College students are heavy users of the Internet and digital media and they have more access to the Internet than most other population segments [9].

On the one hand, by introducing new free and easily accessible information media, shifts in digital technology have broadened the pool of potential readers. A study of 124 EFL (English as a foreign language) students in a university in southern Taiwan, for example, found that $83.9 \%$ of students read online information often every day, while only $31.4 \%$ of them read newspapers and $33.1 \%$ of them read magazines often every day [10]. On the other hand, learning, whether in school or anywhere else, requires time [11]. There is often a trade-off between digital media and studying and/or reading, which is substantial in cases of addiction to video games, a rather common phenomenon among young people nowadays $[12,13]$. Research shows that most of the free time is spent on non-study activities, such as watching TV and playing video games [14]. A study of Taiwan college students [15] found that students who are addicted to the Internet spend on average 5.47 hours on games every week. While this is a general trend among both, American and Asian students, the former ones seem to be more likely to be engaged in non-academic activities. Research shows that in the U.S. approximately $82 \%$ of full-time and $69 \%$ of parttime students admit playing video games [16], which is the case for only 38\% of Chinese students [17]. Video gaming and social networking addiction also may be the reason why reading rates have plummeted in the U.S. In fact, research depicts a rather gloomy situation: literary reading among 18- to 24 -year-olds declined by 28\% between 1982 and 2000. At the same time, home Internet use by this demographic group soared 53 percentage points from 1997 to 2003 [6]. Social networking dominates as a leisure activity among 18-34-year olds, who spend 3.8 hours a day chatting on Facebook, tweeting, etc. [18]. The Pew Internet Project's research (2013) states that $83 \%$ of 18-29-year-olds (prime college age) use social networking sites. An additional corollary of the explosion in digital technology is multitasking. Research indicates that most students use other media while reading or studying [6]. This may have an adverse effect on their comprehension of the material and ultimately on academic performance.

Robert Putnam (1995) [19] has hypothesized that media, particularly TV, crowds out the time that could otherwise be spent on functional activities. Partial support for the time displacement hypothesis can be derived from research related to a relationship between the time spent on reading and studying and academic performance. The impact of this trade-off on academic performance remains a highly debatable issue. Some studies show that there is either no relationship or a weak positive relationship between study time and grade-point average [20-22]. Others find a strong relationship between students' effort and their GPAs, especially among freshmen and sophomores [23,24]. In addition, some studies support the time-displacement hypothesis by indicating a strong positive relationship between grade-point average and time spent on leisure readings $[25,26]$. There are few studies about college students' choices of time allocation between independent academic and non-academic activities. These studies focus either on college students' leisure choices [27] or on the students' reading habits or study time [28]. Moreover, there is currently no body of literature that offers cross-national comparisons of the use of time comparing Chinese and the US students. Yet, in the light of the current 'race to the top', it is important for educators and political leaders to be aware of the efforts that are put forth by today's college students in both superpowers.

\section{Theoretical Background}

Why do Chinese students, from their early years till college life, spend so much more time studying than their American counterparts? A major reason for this striking difference is the motivation for excellence. This characteristic, in turn, is a result of cultural, economic, and historical forces that have shaped and continue shaping the learning attitudes of the youth. The Chinese have been placing a great value on education since the time of Confucius (551 B.C. - 479 B.C.), a great philosopher and educator, whose emphasis on virtue, natural order, respect for authority, selfgrowth and learning has had a profound impact on the values of Chinese for more than 2,000 years. Promotion of education by local officials educated local elite, and central governments date back to Han Dynasty (200-100BC) and meritocracy and bureaucratic organization of the society have endorsed Confucius principles for centuries to come [29]. This historical meritocracy and Confucius traditions have now mingled with modern economics. The Chinese also value education so much because opportunities for the uneducated in a country of more than a billion people are limited [30]. Although in the United States education is also viewed as a stepping stone to success, one does not necessarily have to graduate from college to become wealthy. Bill Gates and Steve Jobs, however exceptional, are more likely to be an American phenomenon than a Chinese one. Therefore, Chinese children - especially only children due to the One Child Policy - are under a lot of pressure to excel in school and are more likely to spend longer hours studying than American students [31]. The underdevelopment of China's financial system and inefficiency of the social safety net add to the pressure as well. Lack of a variety of financial instruments as well 
as institutions that would ensure a steady flow of income, especially for the elderly, often means that a child, usually a boy, becomes a better and often the only insurance for the old age of the parents [30].

In addition, there is also an unspoken code of conformity that is most singularly manifested in a concept of 'face,' an idea that can be somewhat related to a Western concept of 'honor,' although not literally analogous. [31]. Since Chinese culture emphasizes learning and cultivating self-growth, doing otherwise may result in 'losing face.' Therefore, Chinese youths feel more pressure than their American counterparts to avoid humiliation and embarrassment. Their parents feel this pressure too since a bad student will bring about embarrassment to the family, their ancestors, and everyone affiliated with them [32]. Chinese parents, therefore, are more likely to enroll their children in a variety of after-school activities to enhance their academic development and to establish an environment conducive to learning. Television, computer games, and playtime are often given low or no priority in favor of academic pursuits. Intense pressure and a competitive atmosphere abate slightly once the child enters college. Yet, the general pattern remains the same as social, economic, and traditional influences keep pushing students toward academic excellence in the hope of securing a good future.

\section{Key Research Questions}

This study explores differences between samples of Shanghai and NYC college students' perceptions and attitudes toward the allocation of time between out-of-classroom academic activities (studying and reading) and non-academic activities (social network surfing, video gaming, and TV watching). Are there significant differences in the time students in the two countries spend on average on studying and reading? Do they feel that non-study activities crowd out their valuable time spent on academic ones? What would they do if they are not permitted to engage in some of the non-academic activities? Because college students' study habits are formed much earlier in life, when children were under their parents' guidance and control, the study also probes parents attitudes toward the use of time while the college students were young children. When did they allow their children to start playing video games? Does the starting age differ in the two nations? In which country were parents more likely to restrict the hours of playing and the content of video games? The next section describes the research methodology which is then followed by a depiction of the results and the implications for research and practice.

\section{Data Description and Methodology}

\section{Participants}

The respondents in this case study were 201 U.S. students and 156 Chinese students enrolled in business/economics courses at Pace University in New York City and at the University of Shanghai for Science and Technology in Shanghai (USST). Chinese students were enrolled in the joint U.S. -China program between School of Foreign Languages at USST and Queens College of CUNY (City University of New York), under which the students take several business/economics courses taught by American instructors in English. American students were mostly business, finance, and economics majors. About 55\% of U.S. students and 51\% of Chinese students have at least one parent with a university degree. Both groups exhibited similarities in a sense of middle-class parentage, the relative level of income, and urban educational setting. In addition, the two universities share the same inception date and have a somewhat similar ranking. (Note 1). There were $42.3 \%$ male and $57.7 \%$ female respondents at the US university, $43.7 \%$ of whom were freshmen, $26.9 \%$ sophomores, $10.9 \%$ juniors, and $18.5 \%$ seniors. There were $23 \%$ male and $77 \%$ female responders at a Chinese university. The overrepresentation of females is due to the traditional population break down on the campus of the School of Foreign Languages $54.5 \%$ of them are sophomores, $43.6 \%$ are juniors, and $1.9 \%$ are seniors). Because the students at this university are required to take intensive English Language coursework prior to their enrollment in business/economics courses, no freshmen could participate in the study.

\section{Method}

A 16-question survey was designed for this study to determine how students use their time. The respondents were asked how many hours a week they spend on average at different activities, including working/interning, studying, reading for leisure, social networking (Facebook, RenRen (Note 2), etc.), watching TV or shows on the Internet, and playing video games. In addition, the survey had questions related to parents' attitudes toward video games. It probes whether the parents allowed them to play video games when they were kids, whether they limited the hours played and/or censored the content, whether they played with them, as well as the age at which the students started playing the games. These questions offer insight into the earlier development of attitudes of university students in the US and China towards studying and leisure time. To check the perceived trade-off between study time and time spent playing video games, the students who played video games were asked the question "How to have video/ computer games impacted your study habits?" The answers "not at all", "somewhat", and "very much" were assigned numbers 0 , 1 , and 2 respectively. Weighted averages were then calculated to compare the Chinese and American students. The students were also asked what activity they would most likely get engaged in as an alternative to video/computer games. Among the answer, choices were "study more," "read more," "watch TV more," "exercise more," "socialize more," and "try to find a way to play video games anyways." To ensure that students in both countries understood the questions clearly and in a similar fashion, a pilot survey was given to a random sample of 20 students in the United States and 
20 students in China. The final survey was adjusted based on the answers to the pilot survey.

\section{Findings}

\section{The Use of Time}

The results of the survey indicate that both the US and Chinese students spend almost the same amount of time working or performing internships (19.3 and 18.5 hours per week, on average). Yet, American students are more likely to have a job or internship than their Chinese counterparts (44\% of US sample students work or intern, as opposed to $30 \%$ of Chinese students). They also spend the same amount of time watching movies/shows via TV or the Internet - about 9 hours per week, on average. It is interesting to note, however, that in the U.S., male students tend to spend more time watching movies/shows than female students do (10.7 and 7.8 hours per week, on average), while in China it is the opposite (male students spend 8.3 hours per week, on average; female students spend 10.4 hours per week, on average). The fraction of students who play video games and the amount of time spent playing them are essentially the same in both countries $-72 \%$ of Chinese students and 73\% of American students play video games, for about 6 hours per week, on average. In both countries, male students tend to spend more time playing games. Chinese male students spend almost twice as much time, while American male students spend almost three times as much time playing video games as their female classmates. Chinese students spend more time on social networking -- almost 10 hours a week, on average, compared to 6.4 hours, on average, spent by the American students. In the U.S., both genders seem to spend the same amount of time on Facebook. In China, however, social networking seems to be a predominantly female activity - female Chinese students spend almost 2 hours more on RenRen than their male classmates. Chinese students also are a little more likely to shop online - about 3.1 hours a week, on average, compared to 2.3 hours per week, on average, spent by their American counterparts.

The most striking difference, however, is manifested in the hours spent on out-of-classroom learning activities - studying and reading for leisure. Chinese students spend much more time doing both. In fact, they spend more than twice as much time both reading and studying. On average, they read for 9.6 hours per week, on average, and study for 22.3 hours per week, compared to 4.4 hours per week of reading time and 9.1 hours per week of studying time for US students. Female students tend to study longer hours in both countries than males do. The results also indicate that there are very few students in China who don't read (less than $1 \%$ said " 0 hours a week" and 5.1\% said that they read for one hour or less per week) or don't study (only 1.3\% said that they study for one hour or less per week). In the U.S., $10 \%$ of students reported 0 hours of reading per week and about one-quarter of students say that they read for one hour or less per week. Seven percent of US students basically don't study at all (less than one hour a week). It is possible that some differences between the samples' responses related to their study time could be attributed to the specifics of the program Chinese students are in. Since they are taught in a foreign language, they might spend more time studying, as they need to devote additional time to master the language or because learning any subject in a language other than their native one might require more time. In addition, study time might increase as students must overcome problems of studying in a quasi-English environment, with no native English-speaking classmates. However, it is reasonable to assume that an increase in study time due to these factors is not substantial since, to be enrolled in a Foreign Language College, the students had to be already proficient in English. Also, since USST has well established formal collaborations with many universities in America and Europe, Chinese students in the USST-Queens College program study side by side with international students. This alleviates some of the difficulties associated with learning in a language other than native and thus makes the US sample and the Chinese sample more comparable. Overall, a greater number of US students (63.2\%) than Chinese students (42.3\%) spend more time on non-academic activities (social networking, watching TV and YouTube, playing video games, and Internet shopping) than on independent academic ones (studying and reading). However, the students in the two countries differ in terms of how many hours they spend per week on average on each category. While Chinese students spend 32 hours per week studying and reading and 28.5 hours per week on non-academic activities, the US students spend only 13.5 hours per week studying and reading and 23.7 hours per week playing games, social networking, Internet shopping, and watching movies and shows. A total sum of hours spent on both types of the activities together reveals that Chinese students about 22 hours more (a total of 78.9 hours, compared to 56.6 hours spent by American students).

But what about parents' attitudes toward some of the nonstudy activities during the students' early years, at the time when their study habits were being shaped? The results of the survey confirm the differences in parents' attitudes toward those activities, reflecting the differences in the two countries. American college students who were polled started playing games earlier than their Chinese counterparts. On average, the starting age for the American sample was 7.7 years, while for Chinese it was 11.3 years. In both countries, boys seem to have an earlier start than girls. American boys start playing games as early as 7 years old, while American girls start a year later. In China, boys start when they are 9.4, while girls do not play games until the age of 12 . In addition, Chinese parents are more likely not to allow their children to play any video games. In fact, $26 \%$ of the Chinese responders said that they were forbidden from playing video games, compared to only $4 \%$ of their American counterparts. In China, parents are also more likely to limit the hours of playing ( $61 \%$ of them do so, compared to $41 \%$ of 
American parents). Twice as many American parents do not care about the hours or the content of games played $23 \%$ compared to $11.5 \%$ ). Given these striking differences in parental attitudes toward the allocation of time between independent academic and non-academic activities during the early years when their children's study habits are developing, it is not surprising to find that by the time children enter college, their use of time is reflective of the different upbringing.

\section{Students' Perceptions and Attitudes Toward Video Game Playing and Restrictions}

The differences in values placed on reading and education, in general, are also manifested in the ways the students perceive the existing trade-off between academic and non-academic activities. The U.S. college students who play games are less likely to report that video games have an adverse impact on their study habits than their Chinese counterparts. In fact, $57.6 \%$ of American college students reported that there is no effect whatsoever, compared to $48.7 \%$ of Chinese students who think so. Only $35 \%$ of American students think that there is "some effect" and 5.5\% think that there is a "strong effect," compared to $55.8 \%$ and $6.2 \%$, respectively, of Chinese students who chose these answers. What are the students' attitudes toward the restrictions imposed on them by their parents? What if there is no easy access to video games? The differences between the two groups of students are stark. An overwhelming majority of Chinese students reported that in this case they would either study or read more (91\%), while only 13\% of American students chose this answer. Moreover, American students are more likely to find another way to play video games (7.6\%), while much fewer Chinese students chose this answer (1.8\%). The results confirm the difference in the emphasis on studying and reading in the two cultures. Chinese students place an exceptionally high value on educational activities. In 2009, the Chinese publishing institute conducted a nationwide study on the reading habits of adults aged 18 to 70 years. The findings that were disclosed to the press in 2010 revealed that more than two-thirds (69 percent) of Chinese people believe that reading is important for their own development and that this trend is predominantly manifest in the 19 -29-year-olds. The report concluded that younger and better educated Chinese read considerably more books than the rest of the population [33].

The results of our survey indicate that American students have priorities different from those of their Chinese counterparts. Most polled American students said that if they have no easy access to video games, they would watch TV more (31.8\%). Their next favorite 'trade-off' activity is exercising (26\% of American students in the sample said they would exercise more). Socializing is in the third position (17.4\% said they would socialize more). Watching TV is the second most frequently chosen activity for Chinese students (30\% said they would watch TV more). This was followed by socializing ( $28 \%$ chose this answer). Exercising was in the fourth position, which confirms the general observation that the
Chinese do not pay as much attention to sports or exercising as the American youths do. The Survey of American College Students that polled 400+ randomly selected American college students reported that $22.47 \%$ of the students in the sample participate in intramural athletics, including more than $28 \%$ of students aged 19 or younger [34]. Chinese parents are not as much interested in sports activities for their children unless those activities lead to the participation in Olympic Games.

\section{Conclusions and Implications}

This case study helps to investigate differences between the attitudes of Chinese and American college students toward learning. It also explores the students' perception of the trade-off between the time they spend on non-academic activities (watching TV, surfing the net, playing video games) and independent study. Survey results indicate that both U.S. and Chinese students spend almost the same amount of time working or interning, watching movies/shows via TV or the internet, and playing video games. There are, however, some gender differences. Chinese male students spend almost twice as much time, while American male students spend almost three times as much time playing video games as their female classmates. While in the U.S. both genders seem to spend the same amount of time on the social media website (Facebook), in China, RenRen is mainly utilized by female students. The most remarkable difference was found in the hours spent on independent academic activities - studying and non-homework reading. Chinese students spend more than twice as much time on both activities. Female students in both countries tend to study more hours than male students do. An overwhelming majority of Chinese students reported that if they had no easy access to video games, they would either study or read more, while most of the sampled American students said they would watch TV more. In addition, American students are more likely to find another way to play video games. The survey also probed the attitude of parents toward video games at the time when college students were still in school. According to the results, American parents allow their children to start playing at an earlier age and are less likely to limit play hours. These findings confirm the striking differences in the two cultures' positions on educational attainment and commitment to educational goals. These differences are possibly a result of historical traditions, economic and demographic forces, and social values. It is probable that the Confucian philosophy of learning, high marginal returns on education in the fast growing economic environment, and extremely competitive labor markets, force Chinese college students to spend much greater amounts of time on study. Chinese students might face fewer job market opportunities if their academic credentials are not very strong. In addition, the weak structure of saving institutions, especially pension funds and mutual funds, in combination with cultural tradition of saving one's "face" and the need to care for the elderly, might encourage Chinese parents push their only children harder 
as they view their offspring's success as a guarantee of their own financial security during old age. Literature shows that Chinese families place a great value on education thus, children since their early age spend considerable time studying and reading. Our study presents empirical evidence that suggests that these tendencies are exhibited among university students, free from parental influence when studying at college.

Studies show that American students, in contrast, do not spend as much time studying and reading during earlier school years. As this study demonstrates, the trend continues into their college experiences as well. Although American and Chinese college students spend approximately the same amount of time on the internet and digital media, the results of the survey indicate that on average Chinese students start playing video games at a later age (there is more than 3 years' difference). Because study habits are formed during this period (primary school age), it is safe to assume that video games and digital media have a larger detrimental effect on time management of American students than that of their Chinese counterparts. By the time they are in college, Chinese young adults can manage their time in a more efficient, academicfocused, way. Overall, there is a greater number of U.S. college students who spend more time on non-academic activities than on academic ones. It is interesting to note that Chinese students spend about 22 hours more on both types of the activities together. This poses a paradox. Where does the time go for American students? Why do American students spend less time, on average, on both, independent academic and non-academic activities? Further research is necessary to explain this paradox. Perhaps, there is a need for a more detailed survey in which the responders not only report the number of hours spent on digital media, but also on the activities that are beyond the scope of this study, such as exercising and socializing. These activities, as well as some other co-curricular and extracurricular activities, may have some indirect or not easily discerned benefits for college students' academic success.

Some studies suggest, for example, that students who use social media more often are more likely to be self-confident and have a sense of social trust and citizenship responsibility [35,36]. There is certainly room for further investigation and a larger sample of students would perhaps improve the validity of conclusions drawn here and help answer other important questions such as: How much social capital do college students in the United States and China accumulate, if any, when they spend time in their relative social networks (Facebook and RenRen)? What are marginal benefits of extra time spent on extracurricular activities by American students? How does a much stronger emphasis on sports benefit American students when they are about to compete in labor markets? Does time spent playing video games affect students' academic performance similarly in both countries? In addition, further studies may explore the effects of the extra time spent by Chinese students on out-of-classroom academic activities on their academic performance and a comparison can be made with the scholastic performance of American students. To improve stereotypical understanding of Asian and particularly Chinese students, it is also important to go beyond the cultural explanations to explore the reasons behind Chinese students' willingness to devote so many hours to academic-related activities. Although it draws from small samples of students at two colleges in the United States and China, this research does raise concerns regarding the relative future competitiveness of the two superpowers in global labor markets [37-39]. Education and skills will ultimately determine the preparedness of the youth for the real world and if American college students do not invest as much time in studying and reading as their Chinese counterparts do, they might limit their access to better-paying and more rewarding jobs globally.

\section{Notes}

a) Note 1: The ranking system in China is very different from the one in the USA. Although the USST is nominally a Gaokao (national college entrance examination) Tier 1 university, students from provinces have different standards of marks on a Gaokao examination for entering USST $[40,41]$. This lowers the USST's ranking to Tier 2, which makes USST and Pace University students more comparable. Although USST is a public institution (as opposed to Pace University), students who are enrolled in USSTCUNY program must pay an additional tuition fee.

b) Note 2: RenRen is an equivalent of Facebook in China.

\section{References}

1. Chen C, Uttal DH (1988) Cultural Values, Parents Beliefs, and Children's Achievement in the United States and China. Human Development 31(6): 351-358.

2. Stevenson H (1994) Learning Gap: Why Our Schools Are Failing and What We Can Learn from Japanese And Chinese Education. Simon and Schuster.

3. Li J (2003) The US and Chinese cultural beliefs about learning. Journal of Educational Psychology, 95(2): 258-267.

4. Li J (2005) Mind or Virtue Western and Chinese Beliefs about Learning. Current Directions in Psychological Science 14(4): 190-194.

5. Reading Worldwide (2012)

6. National Endowments for Arts (NEA) (2007) To Read or Not to Read: A Question of National consequence. Research Report p. 47.

7. Moffatt M (1989) Coming of Age in New Jersey: College and American Culture. New Brunswick, NJ: Rutgers University Press, USA.

8. Liu Z (2005) Reading behavior in the digital environment: Changes in reading behavior over the past ten years, Journal of Documentation 61(6): 700-712.

9. Kim JH, LaRose R (2004) Interactive e-commerce: Promoting consumer efficiency or impulsivity? Journal of Computer-Mediated Communication $10(1)$.

10. Shen LB (2006) Computer technology and college students' reading habits. Chia-Nan Annual Bulletin 32: 559-572.

11. Bloom BS (1974) Time and Learning. American Psychologist 29(9): 682688. 
12. Morahan Martin J, Schumacher P (2000) Incidence and correlates of pathological Internet use among college students. Computers in Human Behavior 16(1): 13-29.

13. Burgess SR, Stermer SP, Burgess MC (2012) Video Game Playing and Academic Performance in College Students. College Student Journal 46(2): 376-387.

14. Larson RW, Verma S (1999) How children and adolescents spend their time across the world: Work, play, and developmental opportunities. Psychological Bulletin 125: 701-736.

15. Chou C, Hsiao MC (2000) Internet addiction, usage, gratification, and pleasure experience: the Taiwan college students' case. Computers \& Education 35(1): 65-80.

16. Gentile DA (2009) Pathological video game uses among youth 8 to 18: A national study. Psychological Science 20(6): 594-602.

17. Abidin MJZ, Pour Mohammadi M, Lean OC (2011) The Reading Habits of Malaysian Chinese University students. Journal of Studies in Education 1(1): E9.

18. Pew Research Center (2013) 72\% of Online Adults are Social Networking Site Users.

19. Putnam RD (1995) Tuning in, tuning out: The strange disappearance of social capital in America. Political Science and Politics 28(4): 664-683.

20. Lahmers GA, Zulauf CR (2000) Factors associated with academic time use and academic performance of college students: A recursive approach. Journal of College Student Development 41(5): 544-556.

21. Rau W, Durand A (2000) The academic ethic and college grades: Does hard work help students to 'make the grade?'. Sociology of Education 73(1): 19-38.

22. Plant EA, Ericsson KA, Hill L, Asberg K (2005) Why study time does not predict grade point average across college students: Implications of deliberate practice for academic performance. Contemporary Educational Psychology 30(1): 96-116.

23. Michaels JW, Miethe TD (1989) Academic effort and college grades. Social Forces 68: 309-319.

24. Nelson R (2003) Student Efficiency: A study on the behavior and productive efficiency of college students and the determinants of GPA. Issues in Political Economy 12: 32-43.

25. Gallik JD (1999) Do they read for pleasure? Recreational reading habits of college students. Journal of Adolescent \& Adult Literacy 42(6): 480488.
26. Kim JY, Anderson T (2011) Reading across the curriculum: A framework for improving the reading abilities and habits of college students. Journal of College Literacy and Learning 37: 29-40.

27. Yang H, Hutchinson S, Zinn H, Watson A (2011) Discretionary time of Chinese college students: Activities and impact of SARS-induced constraints on choices. Social indicators research 102(3): 517-535.

28. Ebrey PB (2010) The Cambridge Illustrated History of China ( $\left.2^{\text {nd }} e d n\right)$, Cambridge University Press, New York, USA.

29. Dahlman CJ, Aubert JE (2001) China and the knowledge economy: Seizing the $21^{\text {st }}$ century. World Bank Publications.

30. Fong V (2006) Only hope: Coming of age under China's one-child policy. Stanford University Press, Stanford CA, USA.

31. Yuan H, Knapp RG, ed (2010) This is China: The First 5,000 Years. Berkshire Publishing Group, Great Barrington, MA, USA.

32. Lowe ACT, Corkindale DR (1998) Differences in cultural values and their effects on responses to marketing stimuli: A cross-cultural study of Australians and Chinese from the People's Republic of China. European Journal of Marketing 32(9/10): 843-867.

33. Reading Worldwide (2010) Study on the reading habits of the Chinese population.

34. Primary Research Group Inc (2009) The Survey of American College Students: Use of College Athletic Facilities.

35. Valenzuela S, Park N, Kee KF (2009) Is There Social Capital in a Social Network Site?: Facebook Use and College Students' Life Satisfaction. Journal of Computer-Mediated Communication 14(4): 875-901.

36. Ellison NB, Steinfield C, Lampe C (2007) The Benefits of Facebook "Friends:" Social Capital and College Students use of Online Social Network Sites. Journal of Computer-Mediated Communication 12(4): $1143-1168$

37. Carnoy M, Rothstein R (2013) What do international tests really show about US students' performance? Economic Policy Institute.

38. Cook C (7 December 2010) Shanghai tops global state school rankings. Financial Times.

39. Organisation for Economic Co-operation and Development [OECD] (2012) PISA Report.

40. Organisation for Economic Co-operation and Development [OECD] (2009) PISA Report.

41. Pew Internet Project. 72\% of Online Adults are Social Networking Site Users.

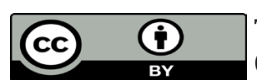

This work is licensed under Creative Commons Attribution 4.0 License

To Submit Your Article Click Here: Submit Article

DOI: 10.32474/OAJCAM.2018.01.000110

\section{OAJCAM}

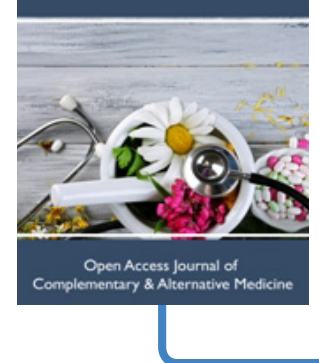

Open Access Journal of Complementary \& Alternative Medicine

\section{Assets of Publishing with us}

- Global archiving of articles

- Immediate, unrestricted online access

- Rigorous Peer Review Process

- Authors Retain Copyrights

- Unique DOI for all articles 